\title{
Wage and Employment Determination through Non-Cooperative Bargaining ${ }^{1}$
}

\author{
by \\ Kevin Roberts \\ Department of Economics, Oxford University
}

May 2007

\begin{abstract}
This paper investigates wage and employment determination by a group of workers or union and a firm, making use of the techniques of non-cooperative bargaining. Previous analyses have examined wage determination with an artificial restriction that employment is determined either before or after wage determination has occurred. Here, employment determination is made part of the bargaining process. With two variables being determined, there is bargaining with a variable pie and solutions correspond to equilibria without commitment. Two different notions of efficiency - exchange and pie efficiency - are relevant and serve to characterise equilibria. Multiple equilibria are shown to arise naturally once exchange inefficient proposals are possible. In all equilibria there is overemployment. Factors which restrict a firm's ability to alter the labour force during or after the wage bargaining process are shown, paradoxically, to benefit the firm.
\end{abstract}

Keywords: Non-cooperative bargaining, Multi-issue bargaining, Non-commitment, Unions

\footnotetext{
${ }^{1}$ I would like to thank Alan Manning, Abhinay Muthoo and John Sutton for helpful comments on early versions of this paper. A version of this paper appeared as a LSE STICERD Discussion Paper, February 1994. The present version has restricted changes to minor editing. I am grateful to those who encouraged me to make the paper more widely available.
} 
JEL Nos: C72, C78, J51, J52 


\section{Introduction}

Many models of bargaining between workers and firm have been presented and such models provide the standard paradigm for wage and employment determination at the microeconomic level. However, it is a commonplace to employ assumptions which should, in a fully satisfactory microfoundation set-up, appear as an implication of the bargaining process. A non-cooperative bargaining approach is not free from ad hoc elements, but it has the principal advantage that the bargaining process with offers and counter-offers appear explicitly and these are based upon a rational assessment of the bargaining process in operation.

In the model of this paper, offers are made sequentially, rationality being captured by restricting attention to subgame perfect equilibria. In this way, the analysis closely follows Rubinstein (1982), which itself when applied to workers-firm bargaining is in the spirit of Zeuthen (1930) and Hicks (1932). But unlike Rubinstein, it is assumed that instead of there being a homogeneous 'pie' to be divided, both bargaining parties are interested in two variables, the wage and level of employment. With two variables, it is possible for outcomes, or proposed outcomes, to be exchange inefficient - there is another wage/employment pair that would make both parties better off. Several authors, notably Leontieff (1946) and, more recently, McDonald and Solow (1981) have suggested that attention should be restricted to exchange efficient bargaining outcomes. It will be shown that whilst exchange efficiency plays an important role is classifying the set of possible equilibrium outcomes, equilibria will in general be exchange inefficient and, in particular, will be characterised by over-employment. The existence of exchange inefficient outcomes also admits the possibility of a delay in agreement which is costly to both parties. Fernandez and Glazer (1990) have exhibited a model where delay can occur in equilibrium though in that model, it is the form of the sequential structure of bargaining which gives rise to delay (see also Haller and Holden (1990)). These papers examine non-cooperative bargaining but assume a homogenous 'pie'. With the possibility of delay, a range of equilibria become possible.

Following a tradition that can be traced back to the monopoly union model of Dunlop (1944), it is assumed that a firm has direct control over the level of employment - the firm has a right-to-manage. In the Dunlop model the workers, who are formed into a union, act as a Stakelberg leader and choose the wage taking into consideration the fact that the firm will choose employment in response to this. Given the restriction 
to a two-stage procedure, the firm will choose an employment level on the labour demand curve. But an unsatisfactory feature of the Dunlop model is that it is implicitly assumed that wage bargaining cannot reopen after employment has been determined. A similar criticism can be made of the literature on union-firm bargaining, e.g. Holden (1989), where it is assumed that employment is determined prior to wage bargaining. Here, the right-to-manage is made part of the bargaining process - during bargaining, the firm can change the labour force and this is recognised by workers.

The problem analyzed in this paper can be construed as one where contracts stay in force for a short time or, in the limit, the union and the firm are free to renegotiate contracts at any time. (In practice, because the underlying economic environment is stationary, no renegotiation occurs once agreement is reached). The monopoly union model, say, is based upon the notion that when the firm changes the labour force, there is no renegotiation of contracts - the model ignores the fact that contracts are of finite duration and that the contract that will be chosen in the future will be influenced by the labour force now being chosen by the firm. In the present model, each party agrees to the contract that is determined through bargaining. The firm, for instance, will not wish to alter the labour force after agreement is reached because it realises that the contract that will then be negotiated starting at the changed labour force will be inferior. With an annual round of wage negotiation, any reasonable discount rate leads both parties to give overriding consideration to the influence of the present contract on future contracts negotiated and this effect is highlighted in the present model.

Workers are assumed to be represented by a single entity - a union. With the union sensitive to the preferences of its present members, its objective will depend upon the current labour force. For the present analysis, the importance of this feature is that the employment level determines both pay-offs and the future preferences of one of the parties to the bargain. Under a right-to-manage assumption, the firm can choose, in part, the preferences of the agent with which it is bargaining and, to discourage the firm from changing employment, the union can make a wage demand that gives to the firm at least as much as it knows it could get from bargaining with the union of any different composition. The value of being in a position to bargain with an agent with different preferences acts like an outside option (Shaked and Sutton (1984b), Sutton (1986)) available to the firm when it is bargaining with the union of some particular composition. This is a central aspect of the analysis. 
It is clear from the above discussion that the present analysis follows the standard literature and treats the union as a single party to the bargaining process. Thus this paper deals with a two party bargaining process and ignores the fact that many individuals, the workers, are involved in the bargain. Interesting issues concerned with the formation of unions cannot be properly addressed within this framework and require an explicit multi-party setting (see Horn and Wolinsky (1988)).

The paper is organised as follows. The basic model is set down in the next section and, in section 3 , the notion of an efficient agreement is examined. The idea of exchange efficiency, where it is impossible to make both parties better off, has been alluded to above. To interpret the equilibria that can arise under bargaining, it is useful to introduce the idea of pie efficiency. In the Rubinstein framework the parties bargain over a 'pie' which is that entity that is shrinking when there is a delay in reaching agreement. A pie efficient outcome involves the maximisation of that entity which is shrinking through delay. The main equilibrium characterisation results are presented in section 4 (proofs are relegated to the appendix) and implications of the results are drawn out in section 5. Concluding remarks are contained in section 6 .

\section{The Model}

We consider a single union and single firm who bargain with each other. The variables to be determined are the wage to be paid - all workers receive the same wage - and the size of the labour force. Figure 1 describes a round of bargaining. The firm first determines the number of its present labour force to fire and the number of recruits to hire. It is assumed that there is a large set of workers who are willing, subject to a reservation wage constraint, to work for the firm; these workers have identical preferences and identical outside opportunities. Because there is a large potential workforce, those fired from the labour force never expect to return to the firm. The hiring and firing possibility makes possible a strategy where the firm gives up negotiating with its present labour force and, instead, negotiates with another group of workers.

Once a new labour force has been determined, the firm makes a wage offer which, if accepted by the union, is implemented. If it is rejected there is a delay of unity before the union can make a wage demand. If this is accepted by the firm then the solution is implemented. If it is rejected then, after a delay of unity, a new round of 
bargaining begins.

The important aspect of the bargaining process is the incorporation of the firm's right-to-manage. This, it could be expected, will limit the power of insider workers as compared to outsiders. Looking at Figure 1, a union wage demand is placed immediately before the stage where the firm can change the labour force. If it was the firm that made a wage offer at this stage then the firm could, in essence, give an ultimatum to the present labour force with no counter-offer from the labour force being possible. The sequential structure of Figure 1 is a simple way of expressing the idea that wage offers and demands are 'cheap' - an alternative set-up would allow the other side to always respond with a counter-offer before changes in the labour force could occur. This set-up produces equilibria similar to those that follow from the sequential structure of Figure 1 and if counter-offers are made at some cost and rejected counter-offers do not influence future behaviour - a Markovian assumption - then the similarity is complete.

In Figure 1 it is assumed that the time between changes in the labour force and the firm's wage offer, is zero. The reason for this is to ensure that minimal changes are made to the Rubinstein (1982) alternating offers bargaining game. In particular, if the right-to-manage assumption is removed and no change in the labour force is permitted, the problem reduces to the Rubinstein model. The ability to change the labour force means the size of the 'pie' to be divided is under the control of one of the bargaining parties - the firm.

We now look at the preferences of the two bargaining parties. It is assumed that bargaining delays the receipt of a surplus which comes from the firm and workers acting together. We deal with the firm's preferences first as these are straightforward. Net of payment for factors other than labour, the firm is assumed to have a volume of surplus product given by $f(\ell) \delta^{t}$ where $f$ is the volume of output and $\delta$ is a discount factor (it is assumed that $0<\delta<1$ ) and $t$ is the time taken to reach agreement. Because of the existence of other factors, $f$ may decline for $\ell$ large. Given a payment of $w$ to workers when agreement is reached, the present value of profits evaluated at date 0 is given by

$$
\pi(w, \ell, t)=(f(\ell)-w \ell) \delta^{t}
$$

This is taken to be the firm's valuation function. Notice that during the course of bargaining, the time to agreement diminishes and the present value of profit increases but there is no change in the relative evaluation of different possible outcomes. 
Turning to the union, we start by looking at the preferences of workers. A worker involved in bargaining for $t$ periods before agreement is reached is assumed to obtain present value utility given by

$$
u(w, t)=v(w-r) \delta^{t}
$$

The utility function $v$ is assumed to be continuous, strictly increasing and concave with $v(0)=0$. The wage in (4) may be viewed as the present value of wage payments and $\delta$, the discount factor, is assumed to be the same as the firm's discount factor. When $w$ is equal to $r$, the worker is indifferent about further delay in reaching agreement; $r$ is a temporary reservation wage which may be viewed either as the value of leisure or as the wage received whilst negotiations take place.

If the worker is fired after $s$ periods of negotiation then utility is given by

$$
\underline{u}(s)=v(\widehat{w}-r) \delta^{s}
$$

The parameter $\widehat{w}$ may be viewed as the permanent reservation wage in the sense that it is the wage available if fired (or if the worker decides to quit). Thus the outside option available to workers is $v(\widehat{w}-r)$ and potential workers will be available to the firm if and only if the prospects with the firm give a return of at least $v(\widehat{w}-r)$. Applying the outside option principle (Shaked and Sutton (1984b)), bargaining will be unaffected by the outside option so long as wage offers and demands exceed the option. To concentrate on other issues, this is assumed always to be the case.

Let $V_{t}$ be the expected utility of a representative member of the labour force at date $t$, discounted back to $t$. If $f_{t}$ and $h_{t}$ is the number fired and hired at $t$ (these will be zero at $t$ odd) then the labour force $\ell_{t+1}$ will be given by

$$
\ell_{t+1}=\ell_{t}+h_{t+1}-f_{t+1}
$$

Using (2) and (3), $V_{t}$ will satisfy

$$
V_{t}=\delta\left[\left(\frac{\ell_{t}-f_{t+1}}{\ell_{t}}\right) V_{t+1}+\left(\frac{f_{t+1}}{\ell_{t}}\right) v(\widehat{w}-r)\right]
$$

if agreement is not reached at date $t$. If agreement is reached at date $t$ then

$$
V_{t}=v\left(w_{t}-r\right)
$$

An implication of (5) is that all members of the firm's labour force at any point during negotiations have identical preferences concerning future negotiations and agreements. 
Given a democratic union that acts in the interest of its members - and membership being equated with the firm's current labour force - the union's objective becomes the expected utility of a representative member at each date. This will be the assumed objective of the union.

One feature of the union's preferences deserves emphasis. These depend upon the wage and employment level eventually agreed upon and the time taken to reach agreement. But the union's preferences are a function of that proportion of its current labour force that are eventually employed and this means that the path taken to reach agreement is important. One way of seeing this is to consider the evaluation of agreements that will be reached after one more period of delay and with minimal disruption to the labour force (no hiring or no firing). If the initial force is $\widehat{\ell}$ then combining (5a) and (5b) gives

$$
V(w, \ell, \widehat{\ell})=\left\{\begin{array}{l}
\delta\left[\left(\frac{\ell}{\hat{\ell}}\right) v(w-r)+\left(1-\frac{\ell}{\ell}\right) v(\widehat{w}-r)\right], \quad \ell \leq \widehat{\ell} \\
\delta[v(w-r)], \quad \ell>\widehat{\ell}
\end{array}\right.
$$

Thus, even in a simple world without both hiring and firing during negotiations, the preferences of the union will depend upon the current labour force. An important aspect of the present analysis is the firm's ability to choose, in part, the preferences of the union with which it negotiates. For instance, the choice of a high labour force could encourage workers to settle quickly because widespread firing will take place when the firm next chooses the labour force. The firm will recognise this and this will help determine the labour force choice by the firm.

\section{Efficient Agreements}

As a prelude to the analysis of equilibria in the bargaining model, we will start by looking at the notion of efficient agreements. With bargaining models incorporating variable 'pie' size, it turns out that there are two different notions of efficiency which may conflict.

The most compelling notion of efficiency comes from the idea that at an outcome, it should not be possible to make both parties better-off. Setting $t=0$ in (1) and $\delta=1$ in (6) gives the preferences of the firm and the union concerning alternative wage and employment configurations if they could be achieved immediately. Starting at a wage $w^{*}$ and employment level $\widehat{\ell}$ which have been established, Figure 2 shows 
the indifference curves of the firm and the union. The iso-profit curves are standard. The curve $\mathrm{L}_{D}$ is the labour demand curve, giving the firm's demand in a competitive market. The curve CC - the contract curve - gives the set of tangencies between the two parties' indifference curves under the assumption that union preferences are given by (6a) for all levels of employment. It touches the labour demand curve at $\widehat{w}$ (the indifference curves underlying (6a) are flat at $\bar{w}$ ) and, by the concavity of $v$, it slopes upwards to the right. But given any established employment level, those workers employed, and hence the union, are indifferent concerning further increases in the labour force: in Figure 2, the union's indifference curves kink at the established employment level. The point $\left(w^{*}, \widehat{\ell}\right)$ is efficient - starting at $\left(w^{*}, \widehat{\ell}\right)$ it is impossible to make both parties better off - and the figure would have been qualitatively similar for all $(w, \ell)$ which lie to the right of the labour demand curve and to the left of the contract curve - this defines the set of exchange efficient wage/employment pairs in the sense that starting at such a wage/employment pair, the union cannot gain without reducing the profits of the firm. Notice in particular that there is no conflict between being on the labour demand curve and efficiency - if a wage/employment pair is established on the labour demand curve then, viewed from this starting point, it is efficient. $^{2}$

The bargaining model under consideration collapses to the original Rubinstein model when the labour force composition cannot be altered. In that model, there is a unique equilibrium outcome which involves an appropriate division (depending upon discount factors) of some 'pie'. An alternative notion of efficiency for a bargaining problem relates to seeking conditions under which the size of the 'pie' is maximised. Assume that the labour force is restricted to be of size $\ell$. Then starting at the second round of negotiations, the firm will ask for some profit $\pi(\ell)$ which is unique (see Rubinstein (1982) and Shaked and Sutton (1984a)). If employment is fixed then at date 1 of the first round of negotiations, workers will prefer an outcome which offers the firm $\delta \pi(\ell)$ - an offer that the firm is willing to accept and gives a higher wage to the workers than they would get from the outcome negotiated, starting at round 2 . This wage will be $w=(f(\ell)-\delta \pi(\ell)) / \ell$. However, at date 0 , the firm only need offer a wage payment of $w^{\prime}$ where $v\left(w^{\prime}-r\right)=\delta v(w-r)$ (see $\left.(2)\right)$ and this gives a profit to

\footnotetext{
${ }^{2}$ This argument is different to Oswald's (1993) where it is suggested that union preferences are flat over the whole space; in that case there is not only no conflict between being on the labour demand curve and efficiency, the efficient set will consist only of the labour demand curve.
} 
the firm which, from the uniqueness of $\pi(\ell)$ must equal $\pi(\ell)$ :

$$
\pi(\ell)=f(\ell)-r \ell-\ell v^{-1}\left[\delta v\left(\frac{f(\ell)-r \ell-\delta \pi(\ell)}{\ell}\right)\right] .
$$

This can be solved explicitly for $\pi(\ell)$ when $v$ is specified. For instance, let $v(w)=\frac{w^{\alpha}}{\alpha}$ so (7) solves to give:

$$
\pi(\ell)=(f(\ell)-r \ell)\left[\frac{1-\delta^{\frac{1}{\alpha}}}{1-\delta^{\frac{\alpha+1}{\alpha}}}\right] .
$$

Corresponding to (8) the wage bill will be given by:

$$
w \ell=f(\ell)-\pi(\ell)=f(\ell)\left[\frac{\delta^{\frac{1}{\alpha}-} \delta^{\frac{1+\alpha}{\alpha}}}{1-\delta^{\frac{1+\alpha}{\alpha}}}\right]+r \ell\left[\frac{1-\delta^{\frac{1}{\alpha}}}{1-\delta^{\frac{1+\alpha}{\alpha}}}\right] .
$$

Equation (8) expresses a sharing rule. The term $f(\ell)-r \ell$ is the 'pie' which is being shared (it is what is being eroded away whilst negotiations proceed). When $\delta \rightarrow 1$, the second term tends to $\frac{1}{1+\alpha}$; when $\alpha=1$, the second term is $\left(\frac{1}{1+\delta}\right)$. If $\alpha=1$ and $\delta \rightarrow 1$ then the second term is one-half; this is the well-known equal sharing rule from Rubinstein (1982).

If the firm could commit itself to a particular labour force at the outset of bargaining then it would choose $\ell$ equal to that which maximises $\pi(\ell)$ in $(7)$ : with an iso-elastic utility function:

$$
f^{\prime}(\bar{\ell})=r
$$

Labour compositions with a larger pie will be termed more pie efficient and full efficiency will result from a maximised pie, e.g. from a size $\bar{\ell}$ given by (10). This is shown in Figure 2. When the utility function fails to be iso-elastic, $\bar{\ell}$ given by $(10)$ will only approximate the pie efficient solution derived from (7).

As Figure 2 makes clear, exchange efficiency differs from pie efficiency. The standard criticism of bargaining solutions that are on the labour demand curve is that they fail to be exchange efficient. ${ }^{3}$ But if the firm chooses the labour force at the commencement of bargaining and is then committed to it then pie efficiency is relevant and the outcome may fail to be exchange efficient. The idea that bargaining models can be laid down which lead to pie efficient solutions is implicit in, for instance, Holden (1989).

To simplify the notation in the next section, it is useful to be able to express equations like (7) neatly. Define:

$$
g(\pi, \ell)=f(\ell)-r \ell-\ell v^{-1}\left[\delta v\left(\frac{f(\ell)-r \ell-\delta \pi)}{\ell}\right)\right] .
$$

\footnotetext{
${ }^{3}$ We have seen, in fact, that exchange efficiency may be implied.
} 
so that (7) becomes:

$$
\pi_{R}(\ell)=g\left(\pi_{R}(\ell), \ell\right)
$$

The solution to $(12)$ is written as $\pi_{R}(\ell)$ to denote the fact that it is the division that will arise in a Rubinstein bargaining problem with $\ell$ fixed. Under concavity of $v(\cdot)$, the function $g$ is increasing in $\pi$ but with a slope strictly less than unity; as $g(0, \ell)>0$ when $v$ is defined $(f(\ell)-r \ell>0)$, there is a unique solution to (12). Finally it is useful to be able to express the commitment bargaining solution diagrammatically. As $w \ell=f(\ell)-\pi(\ell),(12)$ can be used to trace out this solution in $(w, \ell)$ space. This is shown in Figure 3 and labelled RR.

The union's preferences depend upon the current level of the labour force. It is worth noting that preferences are conservative in the sense that preferences favour the current labour force - if $\left(w_{1}, \ell_{1}\right)$ is weakly preferred to $\left(w_{2}, \ell_{2}\right)$ starting at $\ell_{2}$ then this will be the ranking starting at $\ell_{1}$. This explains why the set of exchange efficient outcomes is potentially large. ${ }^{4}$

Finally, it is necessary to draw attention to one other aspect of preferences as this will be used in the proof of Proposition 5 below. Taking any iso-profit curve, the union is made strictly worse off as one moves away from the set of points that are exchange efficient. In particular, if $\ell^{\prime}$ is exchange efficient then, starting at $\ell$ which is exchange inefficient, the union prefers to move to $\ell^{\prime}$. With an obvious change in notation:

$$
V\left(\pi^{*}, \ell, \ell, t\right)<V\left(\pi^{*}, \ell^{\prime}, \ell, t\right)
$$

If union preferences were not a function of the existing labour force then this would be implied by the definition of exchange efficiency.

\section{$4 \quad$ Negotiation Equilibria}

The purpose of this section is to characterize the subgame perfect equilibria of the bargaining model and, in particular, to examine the relationship between equilibria and efficiency. We start by looking at models with elements of commitment and then turn to the non-commitment case.

\subsection{Equilibria with Commitment}

We look at two cases. First, we recall from the last section what happens if the firm first chooses a labour force to which it is then committed. As the problem then reduces

\footnotetext{
${ }^{4}$ If conservatism was systematically violated then the set of efficient outcomes could be empty.
} 
to a Rubinstein bargaining problem, there is a unique equilibrium:

Proposition 1 If the firm commits to a labour force at the outset then the firm chooses a pie efficient labour force and division of the pie is as in the Rubinstein problem.

For comparison purposes, it is useful to consider the other polar case where the parties can commit to the wage bargain and the firm chooses the labour force after the wage has been agreed. This underlies the Dunlop solution and corresponds to a real world situation where wage contracts remain in force for long periods of time. Because agreement to a wage does not bind the firm with regard to employment, an optimal strategy for the firm is, in the event that the bargained wage exceeds $\widehat{w}$, to fire all workers and hire a new labour force, the size of which is determined by the competitive labour demand at the bargained wage rate. Without hiring and firing costs, this is a credible strategy which leads to a bargained wage of $\widehat{w}$. But with an infinitesimally small hiring or firing cost, this strategy is no longer credible - the new labour force will behave just like the replaced labour force - and, after the wage is agreed, the firm will move to a point on the labour demand curve with minimal hiring and firing, i.e. either no hiring or no firing. During the bargaining process, the union and firm will, in essence, make proposals along the labour demand curve and the model becomes a direct extension of the monopoly union model where both sides can make wage offers.

The outcome to this wage bargaining game can be briefly outlined. If the initial union size is small, or if the initial size is large and the labour demand curve is sufficiently inelastic, then the union will strictly prefer outcomes which are further up the labour demand curve and which correspond to a higher wage. The firm's preferences will be exactly the opposite. Given that preferences have this strictly competitive property, the bargaining game is a mild extension of that which led to equation (7), with the labour force size varying with proposed wage/profit changes. If the best the firm can achieve when it makes an offer is profits of $\pi^{\prime}$ (with implied wage $w^{\prime}$ and labour force size of $\ell^{\prime}$ given from the labour demand curve) then, at the previous stage of bargaining, the worst the union can achieve when it makes an offer gives profit to the firm of $\pi^{\prime \prime}=\delta \pi^{\prime}$ (with implied wage $w^{\prime \prime}$ and labour force $\ell^{\prime \prime}$ ). But looking one further stage back, the best the firm can achieve must involve a wage payment of $w^{\prime \prime \prime}$ where $v\left(w^{\prime \prime \prime}-r\right)=\delta v\left(w^{\prime \prime}-r\right)$ and $w^{\prime \prime \prime}$ must equal $w^{\prime}$ by definition. Although it is easy to write down characterizing equations in the general case, the case of $\delta$ close to unity is of particular interest. Then $\ell^{\prime}$ is close to $\ell^{\prime \prime}$ and as $f(\ell)-w \ell$ 
is maximized on the labour demand curve, an envelope condition ensures that the wage/profit opportunities at $\ell^{\prime}$ and $\ell^{\prime \prime}$ are the same whether the labour force is fixed or whether there is movement along the labour demand curve. In consequence, the bargained outcome must therefore be on the RR curve. An exactly similar argument applies to the worst equilibrium for the firm. We thus have

Proposition 2 Assume that there are (small) hiring or firing costs and that there is almost no discounting $(\delta \rightarrow 1)$. If the firm can choose the labour force after wage bargaining and bargaining takes place with a union of small size then the best and worst outcome for the firm will occur on the labour demand curve with division as in the Rubinstein problem - the intersection of the labour demand curve and the RR curve in Figure 3. If this intersection is unique then the outcome is unique.

Comparing this to Proposition 1, the firm prefers a situation where it must commit to a labour force before wage bargaining to a situation where it has the freedom to change the labour force after wage bargaining. Furthermore, whereas Proposition 1 suggests that the bargained outcome will involve overemployment as measured by exchange efficiency, with employment determination occurring after wage bargaining, the outcome is exchange efficient but borders on underemployment outcomes.

If the initial union size is large then the neatness of Proposition 2 is lost and, without specifying the form of the function $v$, it is not possible to usefully characterize the bargained outcome other than to say that it will be on the labour demand curve between the competitive outcome and the outcome given in Proposition 2. However, the qualitative comparison between the outcome and that of Proposition 1 is unaffected.

\subsection{Equilibria without Commitment}

We now look at the case without commitment. Here, there is no reason to believe that there will be a unique equilibrium. Before proceeding to the general case, let us look at Markov equilibria where strategies depend only on the current labour force. ${ }^{5}$ If $\pi_{m}(\ell)$ is the (discounted) profit that a firm will receive in some equilibrium when it has just chosen labour force $\ell$ then it will always choose from those labour forces that maximise $\pi_{m}(\ell)$ giving the firm some profit $\pi_{m}^{*}$. Let the set of equilibrium labour force sizes be $E$. Take any $\ell \in E$ and, starting with $\ell$, consider the outcome $\left(\pi_{m}^{*}, \bar{\ell}\right)$,

\footnotetext{
${ }^{5}$ For simplicity, strategies are made a function of the size of the labour force rather than its composition. The analysis can be generalized and the characterization results continue to apply.
} 
$\bar{\ell} \in E$, that the union most prefers. As union preferences are conservative, $\left(\pi_{m}^{*}, \bar{\ell}\right)$ is the best outcome for the union starting at $\bar{\ell}$. What happens starting at $\bar{\ell}$ ? At $t=1$, the union will wish to make an acceptable offer to the firm (of $\delta \pi_{m}^{*}$ ) and given this, we know that:

$$
\pi_{m}^{*}=\pi_{m}(\bar{\ell})=g\left(\pi_{m}^{*}, \bar{\ell}\right)
$$

Assume that $\bar{\ell}$ is not pie efficient and consider the consequences of the firm choosing a labour force $\bar{\ell}^{\prime}$ where $\bar{\ell}^{\prime}$ is close to $\bar{\ell}$ but more pie efficient. At $\bar{\ell}$, the union strictly prefers to make an acceptable offer at $t=1$ (as $\delta$ is non-zero) so, as preferences are continuous, the union with composition $\bar{\ell}^{\prime}$ will wish to make an acceptable offer at $t=1$ and the firm will obtain profits at $t=0$ given by:

$$
\pi\left(\bar{\ell}^{\prime}\right)=g\left(\pi_{m}^{*}, \bar{\ell}^{\prime}\right)
$$

As $\bar{\ell}^{\prime}$ is more pie efficient than $\bar{\ell}$ we have, $\pi_{R}\left(\bar{\ell}^{\prime}\right)>\pi_{m}^{*}$ and, as $g$ has a slope of less unity in $\pi, \pi_{R}\left(\bar{\ell}^{\prime}\right)-\pi_{m}^{*}>g\left(\pi_{R}\left(\bar{\ell}^{\prime}\right), \bar{\ell}^{\prime}\right)-g\left(\pi_{m}^{*}, \bar{\ell}^{\prime}\right)$. Thus, $\pi_{m}^{*}<g\left(\pi_{m}^{*}, \bar{\ell}^{\prime}\right)$ or, using (15):

$$
\pi\left(\bar{\ell}^{\prime}\right)>\pi_{m}^{*}
$$

which is a contradiction. We therefore have

Proposition 3 In the no commitment case, Markov equilibrium involves the firm choosing a pie efficient labour force and division being determined as in the Rubinstein problem. (The size of the labour force, profits and wages are uniquely determined).

Proposition 3 is a characterization result concerning the equilibrium consequences that follow, starting from the position where the firm chooses the labour force (at $t=0$ ). If the firm is in negotiation with some arbitrary labour force $\widetilde{\ell}$, and then will move to $\widehat{\ell}$ at $t=2$ (with profits $\pi_{m}^{*}$ evaluated at $t=2$ ) then, at $t=1$, the union may wish to wait for the change in labour force. There is a potential for this if $\delta$ is sufficiently close to unity and the union with composition $\tilde{\ell}$ prefers an outcome with profit $\pi_{m}^{*}$ and labour composition $\widehat{\ell}$ to the same profits but composition $\widetilde{\ell}$. This requires $\left(\pi_{m}^{*}, \widetilde{\ell}\right)$ to be exchange inefficient compared to $\left(\pi_{m}^{*}, \widehat{\ell}\right)$. When this delay situation does not arise, the firm attains profits at $t=0$ given by $g\left(\pi_{m}^{*}, \widetilde{\ell}\right)$.

We now turn to the problem of characterising the class of all subgame perfect equilibria. As is well known, as soon as the set of equilibria is non-unique, different continuations can be used to 'bootstrap' a potentially large class of equilibria. Fernandez and Glazer (1990) have noted that in a model which is a minor amendment of the 
Rubinstein model, it is possible to have multiple equilibria, some with inefficient delay (see also Haller and Holden (1990)). In that model, non-uniqueness can be traced to the specific sequential structure of the bargaining process. Here, non-uniqueness will be shown to follow from the tension that exists between exchange and pie efficiency. Once one has good and bad equilibria, it is then easy to obtain 'exotic' behaviour (including delay), this behaviour being promoted by the carrot of a good continuation equilibrium and the stick of a poor continuation equilibrium.

Given an initial labour force $\ell$, a number of different equilibria may result. Looking across all equilibria resulting from an initial choice $\ell$ let $\Pi(\ell)$ and $\pi(\ell)$ be the supremum and infimum of (discounted) profits that can be received by the firm and let $\Pi^{*}$ be the supremum of $\Pi(\ell)$ over all $\ell$ and let $\pi^{*}$ be the supremum of $\pi(\ell)$ over all $\ell{ }^{6}$ When the firm gets to the stage where labour force composition can be changed, it can ensure itself profits of $\pi^{*}$ but can never do better than $\Pi^{*}$.

We start by investigating $\Pi^{*}$. Agreement must be reached during the first round of negotiation (otherwise discounted profits starting at date $t=2$ will be $\Pi^{*} / \delta^{2}$ which itself exceeds $\Pi^{*}$ which is a supremum). But out of this equilibrium, subgame perfect continuations may involve agents making unacceptable offers. Unlike in the Rubinstein problem, there are exchange efficiency gains that can be achieved by waiting. The analysis of equilibria must therefore take into account this possibility.

Looking at $\Pi^{*}$, the argument is similar to that for Markov equilibria except that more care must be taken over the possibility that offers being made will be unacceptable:

Proposition 4 The maximal profit $\Pi^{*}$ that the firm can receive in an equilibrium occurs when the labour force is chosen to ensure pie efficiency and division is as in the Rubinstein problem.

Proof. See appendix.

No matter have complicated the strategies, the firm can do better than the Markov equilibrium. Furthermore, the profits that can be achieved through initial commitment to a labour force provide an upper bound on profits that can be achieved in all no commitment equilibria.

\footnotetext{
${ }^{6}$ Payoffs are indexed by the size of the labour force. These payoffs may be viewed as the suprema and infimia over all compositions giving rise to a particular size.
} 
Looking at Figure 3, It is clear that the equilibrium described in Propositions 1, 3 and 4 may be exchange inefficient; as is clear from the figure, whether pie efficiency and exchange efficiency conflict depends upon whether $r$ is sufficiently below $\widehat{w}$.

We now investigate the lower limit of the firm's profits $\pi^{*}$ which is attained starting with labour force $\ell^{*}$. The labour force $\ell^{*}$ does not depend upon the discount factor $\delta$. However $\ell^{*}$, and through this $\pi^{*}$, is dependent upon $\delta$. Given that the rounds of negotiation may be of short duration, the most interesting case arises when $\delta$ is close to unity. But the case of $\delta$ small is easier to deal with and we start with it. The argument giving rise to Proposition 1 applies and we have:

Proposition 5 For $\delta$ sufficiently small, the infimal profit that the firm can receive in equilibrium is equal to the supremal profit (the labour force is chosen to ensure pie efficiency and division is as in the Rubinstein problem: profits, wages and labour force size are uniquely determined in equilibrium).

Proof. See Appendix.

As $\delta$ falls, the RR curve shifts downwards and acceptable wage offers made by the firm will fall. Unless $r$ exceeds $\widehat{w}$, which appears unlikely, the outside option constraint will be met as $\delta \rightarrow 0$. Although all the propositions assume this constraint does not bind, Proposition 5 will continue to be satisfied when the constraint binds, the only change being that the outside option will dictate the division of surplus.

The case of $\delta$ close to unity is of greater interest:

Proposition 6 Consider the labour force size $\ell^{\prime}$ that maximizes pie efficiency subject to being exchange efficient with profits $\pi^{*}$. Then as $\delta \rightarrow 1, \pi^{*} \rightarrow \pi_{R}\left(\ell^{\prime}\right)$ and this can be sustained by an equilibrium where the firm chooses $\ell^{\prime}$ and division is as in the Rubinstein problem.

Proof. See Appendix.

Propositions 4 and 5 show that with $\delta$ sufficiently small, the firm's equilibrium profit level is uniquely determined and the labour force is chosen for pie efficiency. If pie efficiency is satisfied at an exchange efficient allocation then an implication of Proposition 6 is that profits are again uniquely determined. The main interest of Proposition 6 is the light that it throws on the tension between pie and exchange 
efficiency. There is an equilibrium at a pie efficient allocation and this is the best equilibrium for the firm. Proposition 6 and, in particular, its proof show that if the discount factor is close to unity then the worst equilibrium for the firm must occur at an exchange efficient allocation. The intuition for the result is that at any equilibrium which involves agreement being reached without further changes in the labour force and this must be the case for the equilibrium giving infimal profit to the firm - there is a worse equilibrium involving no agreement without a change in the labour force if the equilibrium is exchange inefficient. Essentially, exchange inefficient potential equilibria are susceptible to a strategy of bargainers that involves a move being made to a more exchange efficient equilibrium which will make both bargainers better off. Exchange inefficient potential equilibria are susceptible to delay in agreement and as the worst equilibrium for the firm must not be so susceptible, it must be exchange efficient.

Finally the preceding argument suggests that the idea that bargaining will result in exchange efficient allocations should, in non-cooperative models, be represented as the idea that as frictions of bargaining become small (the cost of delay being viewed as a friction), allocations that are more exchange efficient than some equilibrium allocations also become equilibria. Notice, however, that even when $\delta \rightarrow 1$, only the most pie efficient of the exchange efficient allocations become equilibria.

\section{Implications}

The purpose of this section is to draw out the implications for union-firm bargaining of the propositions presented in the last section.

The model has the property that the firm has a greater degree of control as captured by the "right to manage". How does the ability to change the labour force influence the bargaining strength of the firm? The firm can change the labour force and use this as a 'threat'. We can abstract from 'threats' by first taking the case where the firm must commit itself to a labour force. Proposition 1 characterises the equilibrium for this case but it is clear that if the roles were reversed then the union would choose a labour force that maximises the union's perceived pie and this would lead to a preferred outcome for the union. This advantage from being able to control the labour force would be present in almost any model irrespective of whether bargaining takes place.

Turning to the 'threat' motive, the firm has the ability during bargaining to alter both the size and composition of the labour force. This ability is a twin-edged sword. 
On the one hand, it allows one to consider equilibria where workers are threatened by a continuation where there will be lay-offs but it also allows one to consider equilibria where, in a continuation, the firm will 'give in' and adjust the labour force to a size preferred by the union. Propositions 1 and 4 show that the ability to change the labour force during bargaining is of no value to the firm and, given proposition 6 , it may be of strictly negative value. Proposition 2 shows that the ability to change the labour force after the termination of wage bargaining can further reduce the firm's profits. It will thus be profitable for the firm to take decisions prior to bargaining which constrain it in its choice of labour force during bargaining. Grout (1984) has demonstrated how firms may be deterred from investing prior to bargaining in the knowledge that the gains from investment will be shared among the firm and workers. The present argument suggests that, prior to bargaining, the firm will be encouraged to invest in technologies which involve little substitutability between capital and labour or to adopt other devices which make changes in the labour force expensive. For example, the paradoxical situation of the firm supporting a generous redundancy scheme may be observed.

The results also make clear that there is no gain from having the ability to replace workers with outsiders. None of the proofs of the propositions of the last section depend upon being able to fire and hire at the same time. The reason for this is simple though important. First, there is a delay cost involved in not reaching agreement with the present labour force. Second, if an insider is replaced by an outsider then the outsider is now an insider and there is no reason for the behaviour of the union to be changed. ${ }^{7}$ The ineffectiveness of being able to replace workers with new workers is a general result that transcends the particular set-up of the present paper (see Shaked and Sutton (1984a) for the first presentation of this argument).

The characterisation results of the last section concentrate on the firm's profit level. Referring back to Figure 3, with union preferences as specified, the pie efficient outcome $\left(\Pi^{*}, \bar{\ell}\right)$ will be exchange efficient as long as $r$ is not too far below $\widehat{w}$. If $r$ is close to $\widehat{w}$ then profits are uniquely determined. Even if this is not satisfied, there may be little variation in profits across different equilibria. For simplicity, let us concentrate upon the case where profits are uniquely determined (see Figure 4) and examine other features of the equilibrium set. Assume that some structural change has occurred

\footnotetext{
${ }^{7}$ When there are multiple equilibria it is possible that the equilibria selection will depend upon the composition of the labour force but this is an uninteresting dependence - the set of equilibria is unchanged.
} 
which triggers wage bargaining between the union and the firm. Assume that both parties are able to make an offer, the firm offering first, before there is a change from the prevailing labour force $\widehat{\ell}$. This is an initial stage added to the structure described in Figure 1. With a discount factor close to unity, there are two possible outcomes:

1. If the union is better off at $\left(\Pi^{*}, \widehat{\ell}\right)$ than at $\left(\Pi^{*}, \bar{\ell}\right)$, then starting at $\widehat{\ell}$, agreement will be reached during the first round of negotiation at a profit close to $\Pi^{*}$.

2. If the union is better off at $\left(\Pi^{*}, \bar{\ell}\right)$ than at $\left(\Pi^{*}, \widehat{\ell}\right)$, then starting at $\hat{\ell}$, there will be a delay and agreement will not be reached until $t=2$ when $\left(\Pi^{*}, \ell^{*}\right)$ will be attained.

Figure 4 shows the set of potential equilibria that can be achieved with appropriate starting levels of the labour force. If the starting position is in the interior of $\left[\underline{\ell}^{e}, \bar{\ell}^{e}\right]$ then as the result of a structural shock, bargaining to a new wage will occur but there will be no change in the labour force. A change in the labour force will take place only if there is a large shock or if there are a series of small shocks that move in the economy in the same direction and, in aggregate, are equivalent to a large shock. If the shock itself is a change in the labour force then the wage bill changes by the change in the value of production - profits are unaffected by the shock (with a discount factor below unity there will be small change to profits).

We have seen that profits are a constant proportion of the maximum 'pie' and this pie is approximately equal to $\max [f(\ell)-r \ell]$ (the approximation becomes exact when $v(\cdot)$ is iso-elastic). The effect of a shock on this pie can be separated into a direct effect and an indirect effect caused by a change in pie efficient labour force; an envelope condition allows this indirect effect to be ignored. It is relevant to note that shocks which lead to an increase in output (or the value of output) will bias the distribution of rewards in favour of profits.

Figure 4 shows that equilibrium can be attained at positions that are to the left of the contract curve and although the firm will never choose a labour force giving rise to an equilibrium to the left of the labour demand curve, an equilibrium at such a position can be sustained after some structural shock. But given the debate concerning models which fail to incorporate 'efficient' bargaining, Proposition 6 is of importance. If pie efficiency and exchange efficiency conflict then when the firm chooses a labour force, the resulting equilibrium will be to the right of the $\mathrm{CC}$ curve: the present model 
predicts unambiguously higher employment levels than those predicted in previous models and, in terms of exchange efficiency, there will be over-employment.

Finally, we note that our analysis has relied upon the fact that wage offers lie above the 'outside option' $\widehat{w}$ (but see the comment following Proposition 5). As is now well recognised, 'outside options' qua 'outside options' place a constraint on offers but, other than this, do not influence the bargained outcome. The only relevance of $\widehat{w}$ is that it in part determines union preferences (Shaked and Sutton (1984b), Binmore, Shaked and Sutton (1989)). The distinction between the 'outside option' $\widehat{w}$ and the reservation price $r$ is important: unlike $\widehat{w}, r$ plays a crucial role in determining the profits that the firm will receive in the bargained outcome.

\section{Concluding Remarks}

This paper has examined the non-cooperative bargaining implications of union-firm wage negotiation. In particular, the analysis has moved away from the problem where a fixed pie is being divided and, by allowing employment as well as wage levels to be determined during the bargaining process, a variable pie has been admitted. This has forced us. to examine the different notions of exchange and pie efficiency and it is of interest that the characterisation of equilibria makes use of both efficiency conditions. The introduction of the possibility of exchange inefficiency has been shown to imply the optimality of behaviour which leads to the rejection of offers and multiplicity of equilibria - within strict bounds - is naturally introduced.

With regard to the application to union-firm bargaining, the model analyzed in this paper can be viewed as a situation where contracts are of short duration or where there is no commitment - the union cannot commit not to make new wage demands, the firm cannot commit not to make new wage offers or to change the labour force. Given that contracts are not written in stone for all time, the analysis casts doubt on other theories of union-firm bargaining. Three qualitative conclusions stand out from this new theory. First, the theory predicts overemployment in unionised firms. Second, the theory predicts that the firm's right-to-manage is of negative value to the firm. In consequence, the firm will gain from procedures which commit it to a particular labour force. In particular, unionised firms will gain from laws that demand generous redundancy provisions and they will be encouraged to adopt methods of production involving job specific skills. Third, looking at the effects of structural shocks, the 
theory provides an explanation for the rigidity of employment levels with wage/profit division being determined by the size of the maximal pie. An implication of this is that retiring workers usually will not be replaced and the efficiency gain resulting will go in its entirety to wages rather than profits.

Finally, we note how the model changes with a change in union objective. If firing must follow a strict rule as in a seniority system with 'last-in-first-out', one can conduct an analysis that parallels the present analysis. The concept of pie efficiency is unaltered but the exchange efficient set becomes the labour demand curve above the wage $\widehat{w}$. The best equilibrium for the firm involves the same labour force choice as with utilitarian preferences - this is also the unique Markovian equilibrium and the commitment equilibrium. The worst equilibrium lies on the labour demand curve and this involves lower profits than the worst equilibrium with utilitarian preferences. Unlike in the utilitarian case, there will always be a range of profits that the firm can achieve so there is more opportunity for 'exotic' equilibria to occur (continuation equilibria acting as appropriate 'carrots and sticks'). 


\section{Appendix}

The purpose of the appendix is to provide proofs of the subgame perfect equilibrium characterisation results presented in the main text. Recall that $\Pi^{*}$ is the highest profit that the firm can attain (with labour force $\ell^{*}$ ) and $\pi^{*}$ is the lowest profit that the firm may have to accept in equilibrium.

Proposition 4. The maximal profit $\Pi^{*}$ that the firm can achieve in equilibrium occurs when the labour force is chosen to ensure pie efficiency and division is as in the Rubinstein problem.

Proof. We know that in equilibrium, $\Pi^{*}$ is attained by choosing some $\ell^{*}$ and agreement is reached during the first round of negotiation. Assume that the union has rejected the firm's offer at $t=0$ and consider the union's offer at $t=1$. For the offer to be acceptable, the firm must be given at most $\delta \Pi^{*}$ and if the continuation from $t=2$ gives the firm $\Pi^{*}$ then the union will have to and will wish to make such an offer. Recalling (11), the firm will make an acceptable offer at $t=0$ and receive:

$$
\widetilde{\Pi}=g\left(\Pi^{*}, \ell^{*}\right)
$$

The other alternative is that the union does not wish to make an acceptable offer at $t=1$ in which case the union can achieve more in a continuation than it will obtain by offering $\delta \Pi^{*}$. At $t=0$, an acceptable offer by the firm will therefore leave it

with profits no greater than $\widetilde{\Pi}$. Therefore, the best that the firm can achieve occurs when the union makes an acceptable offer. The best offer is $\delta \Pi^{*}$ which arises with a continuation at $t=2$ giving rise to $\Pi^{*}$. Thus

$$
\Pi^{*}=\widetilde{\Pi}
$$

and (A1) and (A2) give:

$$
\Pi^{*}=g\left(\Pi^{*}, \ell^{*}\right)
$$

$\Pi^{*}$ is the Rubinstein division at $\ell^{*}$. Now assume that $\ell^{*}$ does not maximize the pie and consider a labour force $\ell$ which is arbitrarily close to $\ell^{*}$ and gives a greater pie. Consider an equilibrium where, starting at any labour force, the firm always chooses $\ell^{*}$ and receives $\Pi^{*}$ when it is given the opportunity. If the initial labour force is $\ell^{*}$ then the union will strictly prefer to make an acceptable offer at $t=1$. As preferences are 
continuous, it will wish to make an acceptable offer at $t=1$ if the initial labour force is $\ell$. Thus, if the firm initially chooses $\ell$ then it will receive profits:

$$
\Pi=g\left(\Pi^{*}, \ell\right)
$$

As $\ell$ is more pie efficient than $\ell^{*}, \Pi^{*}<g\left(\Pi^{*}, \ell\right)$, which follows because $\Pi^{*} \leq \pi_{R}\left(\ell^{*}\right)$ and $g$ has a slope in $\pi$ less than unity (recall the proof of Proposition 3). Thus:

$$
\Pi^{*}<\Pi
$$

which is a contradiction: $\ell^{*}$ is pie efficient and, from (A3), division is as in the Rubinstein problem.

Proposition 5. For $\delta$ sufficiently small, the infimal profit $\pi^{*}$ that the firm can receive in equilibrium is equal to the supremal profit.

Proof. Consider the worst consequences to the firm of choosing labour force $\ell^{*}$. If the firm's offer at $t=0$ is unacceptable then at $t=1$ the union must decide whether to make an acceptable offer. An offer $\delta \Pi^{*}$ will be accepted. For $\delta$ small, $\delta \Pi^{*}$ will be arbitrarily small and, through discounting, the union will prefer to offer the firm this or a lower acceptable amount rather than delay agreement. Thus, the union will make an acceptable offer and, as this cannot be less than $\delta \pi^{*}$, the firm at date 0 will receive profits $\pi$ such that:

$$
\pi \geq g\left(\pi^{*}, \ell^{*}\right)
$$

Now, as $\pi^{*} \geq \pi$ by definition:

$$
\pi^{*} \geq g\left(\pi^{*}, \ell^{*}\right)
$$

But as $\Pi^{*}=g\left(\Pi^{*}, \ell^{*}\right)$ and $\pi^{*} \leq \Pi^{*}, g$ having a slope of less than unity in $\pi$ gives

$$
\pi^{*}=\Pi^{*}
$$

Proposition 6. Consider the labour force size $\ell^{\prime}$ that maximises pie efficiency subject to being exchange efficient with profits $\pi^{*}$. Then as $\delta \rightarrow 1, \pi^{*} \rightarrow \pi_{R}\left(\ell^{\prime}\right)$ and this can be sustained by an equilibrium where the firm chooses labour force size $\ell^{\prime}$ and division is as in the Rubinstein problem. 
Proof. We start by constructing an equilibrium which gives profits to the firm which are less than $\Pi^{*}$ when $\ell^{\prime}$ is not pie efficient $\left(\ell^{\prime} \neq \ell^{*}\right)$. Let $\bar{\ell}$ be any more pie efficient labour force size than $\ell^{\prime}$ such that $\bar{\ell} \neq \ell^{*}$ and $\bar{\pi}=\pi_{R}(\bar{\ell})$. Consider $\ell^{\prime \prime}$ close to $\ell^{\prime}$ which is more pie efficient than $\ell^{\prime}$ but less pie efficient than $\bar{\ell}: \pi_{R}\left(\ell^{\prime}\right)<\pi_{R}\left(\ell^{\prime \prime}\right)<\bar{\pi}$. It will be shown that for $\delta$ close to unity there is an equilibrium - call it the $E(\bar{\pi})$ equilibrium - giving the firm profits of $g\left(\bar{\pi}, \ell^{\prime \prime}\right)$ which, as $\bar{\ell}$ tends to $\ell^{\prime}$, gives $g\left(\widetilde{\pi}, \ell^{\prime}\right)$ where $\widetilde{\pi}=\pi_{R}\left(\ell^{\prime}\right)$. By definition, this profit is equal to $\widetilde{\pi}=\pi_{R}\left(\ell^{\prime}\right)$. [It will then be shown that $\pi^{*}$ is bounded below by $\pi_{R}\left(\ell^{\prime}\right)$ and the result will follow]. The equilibrium takes the following form:

1. If the firm chooses a labour force more pie efficient than $\ell^{\prime \prime}$ then the firm can obtain a profit of $\bar{\pi}$ if it chooses a labour force size of $\ell^{\prime}$ after one round of negotiation. If it chooses some $\ell_{c} \neq \ell^{\prime}$ then the continuation equilibrium is $E(\bar{\pi})$ (giving at most $g\left(\bar{\pi}, \ell^{\prime \prime}\right)$ which is less than $\bar{\pi}$ ).

2. If the firm chooses a labour force $\ell$ no more pie efficient than $\ell^{\prime \prime}$ then the firm can obtain a profit of $\bar{\pi}$ in a continuation if it retains the labour force $\ell$; otherwise the continuation equilibrium is $E(\bar{\pi})$ with some different labour force $\ell_{c}$.

We will show first that the firm can be offered a continuation of $\bar{\pi}$ at different labour force levels. For the equilibria that have been constructed, it is necessary only to show that $(\bar{\pi}, \ell)$ can be sustained as an equilibrium for an $\ell$ where $\pi_{R}(\ell)<\bar{\pi}$. The easiest way to do this is through a randomization device which selects equilibria as with sunspots. ${ }^{8}$ Assume that $\ell$ is chosen and randomization then takes place. With probability $p$, if agreement is not reached during the first round of negotiation then the firm is offered the supremum profit in all continuations (and achieves $\Pi^{*}$ ) and, with probability $1-p$, the firm is offered the $E(\bar{\pi})$ equilibrium in all continuations (and achieves $g\left(\bar{\pi}, \ell^{\prime \prime}\right)$ ). Consider what the firm can achieve when $p=0$. If, subject to agreement not being reached at $t=0$, the union wishes to make an acceptable offer at $t=1$ then the firm will wish to make an acceptable offer at $t=0$ and the firm will receive $g\left(g\left(\bar{\pi}, \ell^{\prime \prime}\right), \ell\right.$ ) which is less than $\bar{\pi}$ (as $\ell$ and $\ell^{\prime \prime}$ are less pie efficient than $\bar{\ell}$ ). If the union does not wish to make an acceptable offer at $t=1$ then this can only reduce the profit received by this firm (as viewed at $t=0$ ). Thus, with $p=0$, the value to the firm of choosing $\ell$ falls short of $\bar{\pi}$. When $p=1$, the firm can wait until $t=2$ and receive $\Pi^{*}$ so the value to the firm of choosing $\ell$ is at least $\delta^{2} \Pi^{*}$ which, for large $\delta$,

\footnotetext{
${ }^{8}$ The randomization device is between different equilibria; in each equilibrium, strategies are pure.
} 
strictly exceeds $\bar{\pi}$. Thus continuity ensures that there is a $p$ between zero and unity which gives expected profit to the firm of $\bar{\pi}$ when it chooses $\ell$. [It is possible to replace this type of mechanism with one where $E(\bar{\pi})$ is offered in continuations but with the knowledge that $\Pi^{*}$ will become available at some date in the future. With $\delta$ close to unity, a date can be chosen to give the firm profits arbitrarily close to $\bar{\pi}$.

We now return to examine the consequences of the rules that have been laid down about continuation equilibria. Given that offers are optimally chosen given these rules, what labour force will be chosen by the firm? Consider first the case of the firm choosing a labour force $\ell$ more pie efficient than $\ell^{\prime \prime}$. If agreement is not reached during the first round of negotiation, it is optimal for the firm to choose $\ell^{\prime}$ and obtain profits $\bar{\pi}$. At $t=1$, the union will not wish to make an acceptable offer if:

$$
V(\delta \bar{\pi}, \ell, \ell, 1)<V\left(\bar{\pi}, \ell^{\prime}, \ell, 2\right)
$$

For $\delta$ close to unity, this will be satisfied if:

$$
V(\bar{\pi}, \ell, \ell, t)<V\left(\bar{\pi}, \ell^{\prime}, \ell, t\right)
$$

which holds because $\ell^{\prime}$ is exchange efficient (recall equation (13)). Thus, at $t=0$, the firm will make an acceptable offer if:

$$
V\left(\delta^{2} \bar{\pi}, \ell, \ell, 0\right)>V\left(\bar{\pi}, \ell^{\prime}, \ell, 2\right)
$$

but this is ruled out by (A9) if $\delta$ is close to unity. Thus, no acceptable offer will be made during the first round of negotiation and the firm will receive $\bar{\pi}$ at $t=2$. Discounting back to $t=0$ gives profits of $\delta^{2} \bar{\pi}$ which falls strictly short of $\bar{\pi}$.

Now consider choosing a labour force size $\ell$ which is less pie efficient than $\ell^{\prime \prime}$. The firm choosing $\ell$ and receiving profits $\bar{\pi}$ as a continuation is equilibrium behaviour so, at $t=1$, the union will wish to make an acceptable offer; thus, at $t=0$, the firm will make an acceptable offer which gives it a profit of:

$$
\pi=g(\bar{\pi}, \ell)
$$

As $\bar{\pi}>\pi_{R}(\ell)$ by assumption, $g$ having a slope less than unity in $\pi$ gives:

$$
\bar{\pi}>g(\bar{\pi}, \ell)
$$

We thus have:

$$
\bar{\pi}>\pi
$$


The optimal strategy of the firm is therefore to choose $\ell^{\prime \prime}$ rather than $\ell$ and obtain a profit of $\bar{\pi}$.

What happens when $\bar{\ell}$ converges to $\ell^{\prime}$ ? The profit resulting from the $E(\bar{\pi})$ equilibrium converges to $g\left(\pi_{R}\left(\ell^{\prime}\right), \ell^{\prime}\right)$; by definition, this is $\pi_{R}\left(\ell^{\prime}\right)$. Thus, for $\delta$ close to unity, $\pi^{*}$ (the infimum profit) must be less than an equal to $\pi_{R}\left(\ell^{\prime}\right)$.

Finally, we consider a lower bound for $\pi^{*}$. Consider any $\ell$ such that $\left(\pi^{*}, \ell\right)$ is exchange efficient. If the firm chooses labour force size $\ell$ then, after one round of negotiation, the continuation will be $(\bar{\pi}, \bar{\ell})$ for some $\bar{\pi} \geq \pi^{*}$. As the union prefers $\left(\pi^{*}, \ell\right)$ to $\left(\pi^{*}, \bar{\ell}\right)$ to $(\bar{\pi}, \bar{\ell})$, discounting ensures that it will wish to make an acceptable offer at $t=1$ with the result that, at $t=0$, the firm will achieve $g(\bar{\pi}, \ell)$. As this cannot be less than $g\left(\pi^{*}, \ell\right)$, the firm can always achieve at least $g\left(\pi^{*}, \ell\right)$ which, by definition, must not exceed $\pi^{*}$. As $g$ has a slope of less than unity in $\pi, \pi^{*} \geq \pi_{R}(\ell)$ and, in particular, $\pi^{*} \geq \pi_{R}\left(\ell^{\prime}\right)$. 


\section{References}

Binmore, K., A. Shaked and J. Sutton (1989), "An Outside Option Experiment", Quarterly Journal of Economics, 104, 753-770.

Dunlop, J. (1944), Wage Determination Under Trade Unionism, New York: Macmillan.

Fernandez R., and J. Glazer (1990), "Striking for a Bargain Between Two Completely Informed Agents", American Economic Review, 81, 240-252.

Grout, P. (1984) "Investment and Wages in the Absence of Binding Contracts: A Nash Bargaining Approach", Econometrica, 52, 449-460.

Haller, H. and S. Holden, (1990), "A Letter to the Editor on Wage Bargaining", Journal of Economic Theory, 52, 232-236.

Hicks, J. (1932), The Theory of Wages, London: Macmillan.

Holden, S. (1989), "Wage Drift and Bargaining: Evidence From Norway", Economica, $56,419-432$.

Horn, and A. Wolinsky (1988), "Worker Substitutability and Patterns of Unionisation", Economic Journal, 98, 484-497.

Leontieff, W. (1946), "The Pure Theory of the Guaranteed Annual Wage Contract", Journal of Political Economy, 54, 76-79.

McDonald, I. and R. Solow (1981), "Wage Bargaining and Employment", American Economic Review, 71, 896-908.

Oswald, A. (1993), "Efficient Contracts are on the Labour Demand Curve", Labour Economics, 1, 85-113. 
Rubinstein A. (1982), "Perfect Equilibrium in a Bargaining Model", Econometrica, 50, 97-109.

Shaked, A., and J. Sutton (1984a), "Involuntary Unemployment as a Perfect Equilibrium in a Bargaining Model", Econometrica, 52, 1351-64.

Shaked, A., and J. Sutton (1984b), "The Semi-Walrasian Economy", STICERD Economic Theory Discussion Paper, No. TE/84/98, LSE.

Sutton, J. (1986) ,"Non-Cooperative Bargaining Theory: an Introduction", Review of Economic Studies, 53, 709-24.

Zeuthen, F. (1930), Problems of Monopoly and Economic Welfare, London: Routledge. 

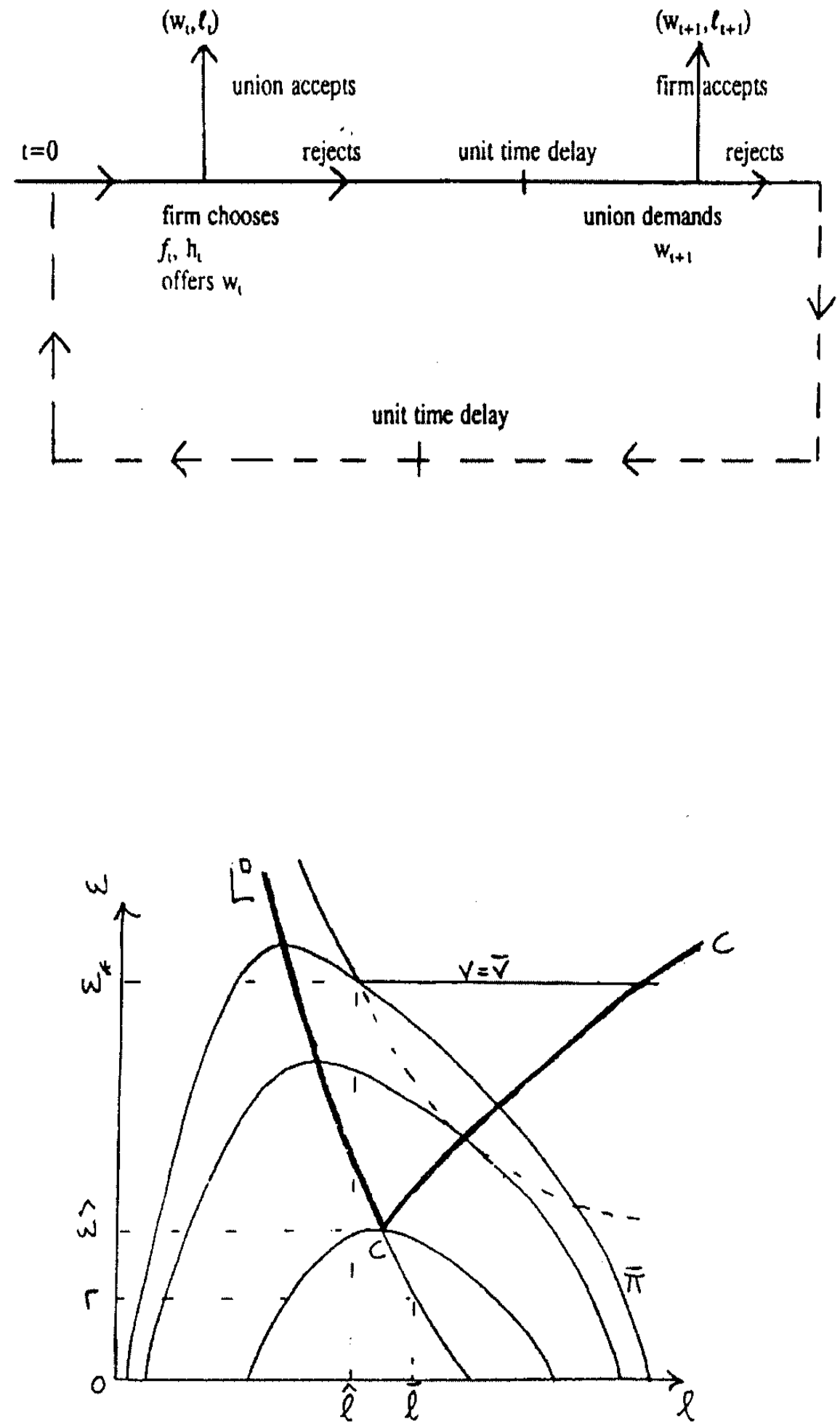

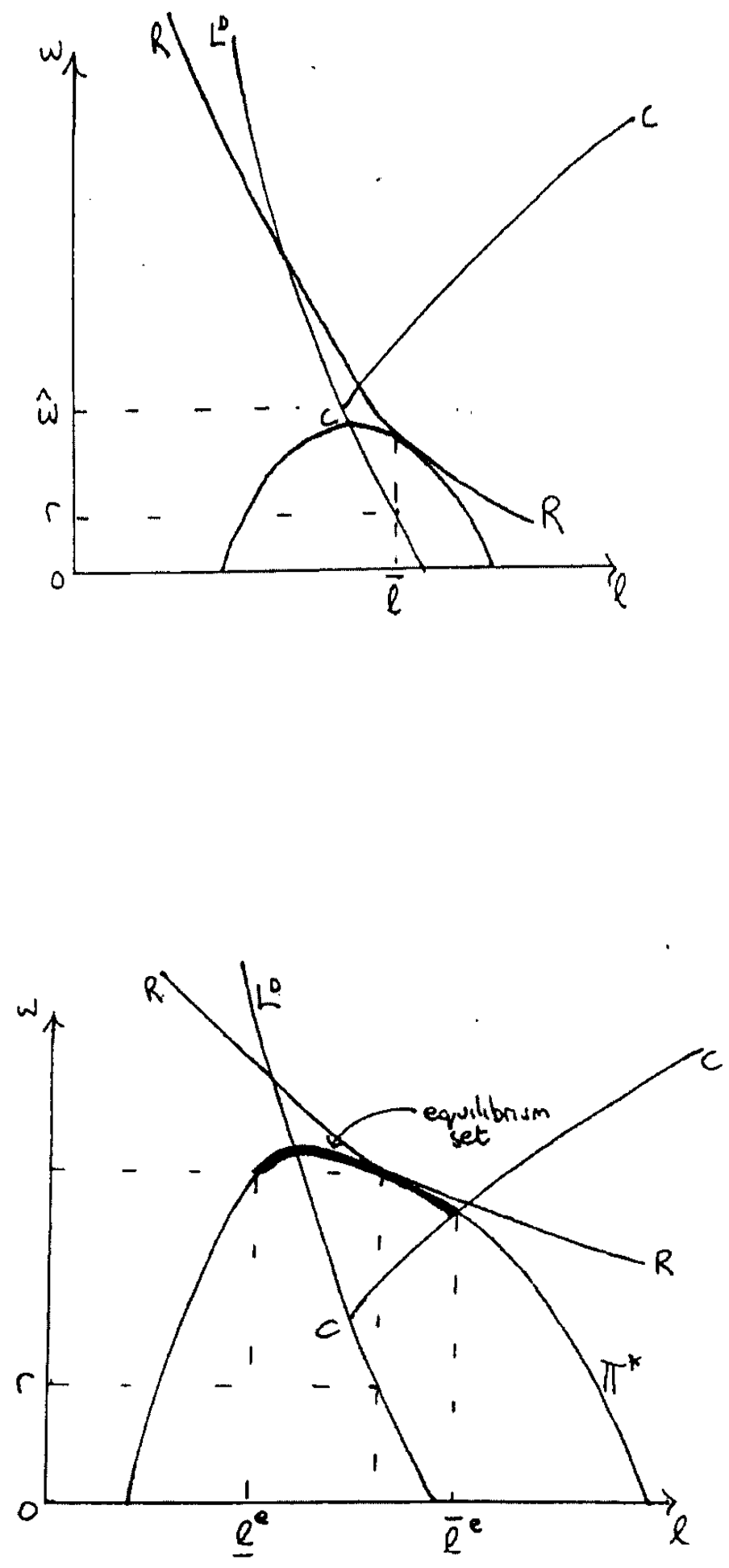

30 